\title{
TRANSLATION AND COSMOPOLITANISM
}

\section{Divya Pradhan}

"Only connect ... and human love will be seen at its highest. Live in fragments no longer."

- E.M. Forster, Howards End

\begin{abstract}
This paper seeks to situate translation of texts as a vital tool in promoting cosmopolitanism. It is mainly through the access provided by translation that one can understands the Other. The power of translating literature to create a cosmopolitan imagination which will foster cosmopolitan empathy cannot be doubted. If Nations are 'imagined communities', there is no reason why a Cosmpolitan world cannot be imagined.
\end{abstract}

"Our ancestors have been human for a very long time" (Appiah: 2006). And since this very long time that we have been human, we have also been characterised by our differentiation. The history of human civilization has been a history of different groups living lives of relative isolation. One could live ones entire life without interacting with someone from a different tribe or race. It was only in the last century that a truly connected world community came into existence. Due to the rapid development in communication technology we have started living lives in a global context. This paradigm shift in human interaction has led to a concomitant change in social science theories. Often called the process of globalisation various theorists have put forth their views on this new dynamics. Roland Robertson defines globalisation as, "the compression of the world and the intensification of a consciousness of the world as a whole". 
Ulrich Beck calls for a shift from 'methodological nationalism' to 'methodological cosmopolitanism' (Beck: 2006). Beck calls cosmopolitanism "the defining feature of the new era, the era of reflexive modernity, in which national borders and differences are dissolving and must be renegotiated in accordance with the logic of 'politics of politics' "(ibid:2006) He sees in this outlook a way forward from the "self-centred narcissism of the national outlook and the dull incomprehension with which it infects thought and action, and hereby enlighten human beings concerning the real, internal cosmopolitanization of their life worlds and institutions" (ibid: 2006).

This paper seeks to situate translation of texts as a vital tool in promoting cosmopolitanism. It is mainly through the access provided by translation that one can understand the Other. The power of translating literature to create a cosmopolitan imagination which will foster cosmopolitan empathy cannot be doubted. If Nations are 'imagined communities', there is no reason why a cosmopolitan world cannot be imagined.

It is important at the outset to distinguish between Globalization and Cosmopolitanism. Globalization is a process of interaction and integration among people, companies, and government of different nations, a process driven by international trade and investment and aided by informational technology (http://www.globalization101.org/). Cosmopolitan on the other hand eludes a standard definition. The Cynics of 4th century B.C. coined the term cosmopolitanism. Unlike a 'citizen' who belonged to a polis the 'cosmopolitan' on the other hand belonged to the cosmos. It also meant that the duties and responsibilities of the individual spread beyond the polis and the kin. If one belonged to the entire cosmos one was also responsible for everything in the cosmos. Seen as a universalistic perspective it has often been derided as an elitist concept. A cosmopolitan often being seen as a jet setting elite free from the concerns of the regional and the particular. Cosmopolitanism, today however is understood differently. Cosmopolitan necessitates a defiance of positive and 
definite specification as it would be " an uncosmopolitan thing to do" (Breckenridge:1).

"The Cosmopolitans of our times does not spring from the capitalized "virtues" of Rationality, Universality, and Progress: nor is it writ large in the figure of the citizen of the world. Cosmopolitans today are often the victims of modernity, failed by capitalism's upward mobility, and bereft of those comforts and customs of national belonging. Refugees, people of diaspora, and migrants and exiles represent the spirit of the cosmopolitical community" (Breckenridge:6)

"Like nations, cosmopolitanisms are now plural and particular. Like nations, they are both European and nonEuropean, and they are weak and underdeveloped as well as strong and privileged. And again like the nation, cosmopolitanism is there- not merely an abstract ideal, like loving one's neighbour as oneself, but habits of thoughts and feeling that have already shaped and been shaped by particular collectivities, that are socially and geographically situated, hence both limited and empowered." (Cheah \& Robbins : 2)

There are two contrary views regarding cosmopolitanism. It is either seen as an abstract idea which can never be implemented and which is actually a sheep skin to the wolf that is economic globalisation or it is seen as a necessary tool against the narrow mindedness of patriotism. However it is too late in the day to discuss the possibility of cosmopolitanism. The world has become cosmopolitan. Good and Bad politics, ideas, food, films, music, disease, medicines travel globally. However, as different groups encounter one another, it has not necessarily only fostered, a shared sense of humanity. Globalization has not led to widespread homogeneity. In fact it has led to an increasing counter movement of fear of the Other and seeing oneself as uprooted and alienated. As Maalouf writes: "This is because all communities and cultures have a sense that they are up against others stronger than they, a feeling that they can no longer keep 
up the heritage safe. Looked at from the South and East, it is the West that dominates. Looked at from Paris it is America that holds sway. But when you go to the United States then what do you see? You see minorities reflecting all the diversity in the world, all needing to assert their original allegiance. and when you have met all the minorities and been told a hundred times that power is in the hands of the white males, or of Anglo-Saxon Protestants, you suddenly hear the sound of a huge explosion in Oklahoma City. and who are the people responsible? Some white male Anglo-Saxon Protestants who regard themselves as members of the most neglected and despised of minorities, and who believe that globalization is sounding the knell of 'their' America" (Beck: 2006).

This fear often manifests itself in form of rabid racism often accompanied by violence. The transmission and acceptance of the material culture of the Other has not necessarily led to an understanding and respect for the nonmaterial culture of the Other. This is where translation can bridge this gap between the acceptance and non acceptance of material and non material culture. Octavio Paz says that translation is "the principal means we have of understanding the world' (Bassnett \&Trivedi: 1999).

Translation derived from the Latin word 'translatio' means "carrying across". It has a history as ancient as cosmopolitanism and has been used to transmit ideas and texts from a source language to a target language. Inspite of the 'instanteinty' offered by the modern communication technology and the plethora of information available on our fingertips we remain largely ignorant to the Other, especially the ones that have been left on the fringes in the asymmetrical power relations as a consequence of economic globalisation. This 'blank' space that is in our imagination vis-a-vis the other can be filled by the familiarity brought about by texts. If literature is the making sense of life through texts then the process of translation will also foster an understanding of Other lives through these texts. "Literature, in particular, constitutes an especially sensitive gauge of sentiments of belonging: creating or 
consuming literature meant for large worlds or small places is a declaration of affiliation with that world or place. The production or circulation of literature, accordingly, is utterly unlike the production or circulation of things. The universalization of particular technologies or the particularization of universal ones that characterize a dominant form of contemporary globalization carries no hint of belonging; the practices of literary culture, by contrast, are practices of attachment" ( Breckenridge: 18). Now more than ever is the need to understand the cultural other. The role of translation in fostering global understanding has often been understated. As we experience life globally there is also a sense of a shared destiny. Nothing remains constricted by national boundaries today. Ideas travel faster than ever before. The Arab Spring was not limited to one country. The Syrian Crisis has affected Europe in the form of thousands of migrants at its doorsteps seeking asylum. The Swine Flu, Bird Flu, Ebola and other contagious diseases are transmitted must faster across national borders. Ideas of democracy, human rights, freedom of press are disseminated at the same speed as ideas of intolerance and extremism. If the Korean Psy's 'Gangnam style' made the world dance to his new moves, an Indian actor Dhanush also made the world croon 'Kolaveri di'. It is not only countries like Bangladesh and Maldives that will be affected by global warming. In the recent past France experienced a heat wave that killed many. As the nations realise that isolation and insularity are not a luxury they can afford, cosmopolitanism seems and is inevitable. National boundaries become redundant as the flow of ideas and goods can't be restricted and controlled. Sheldon Pollock aptly says, "Cosmopolitanism, in its wide and wavering nets, catches something of our need to ground our sense of mutuality in conditions of mutability, and to learn to live tenaciously in terrains of historic and cultural transition" ( Breckenridge: 4). Seen in this context, cosmopolitanism, can be empowering. Its fundamental distinction is that it is devoted to the welfare of humanity unencumbered by local ties as Bruce Robbins writes, "It has a new cast of characters...Caribbean au pairs in the United States, Egyptian guest workers in Iraq, Japanese women who 
take gaijin lovers". (Cheah \& Robbins: 1998). As an empowering tool cosmopolitanism according to Paul Rainbow should be defined as, "an ethos of macro-interdependencies, with an acute consciousness (often forced upon people) of the inescapability and particularities of places, characters, historical trajectories, and fates." (Cheah \& Robbins: 1998). That is why it is correctly referred to in its plural form as Cosmopolitanisms.

However this global movement of material and nonmaterial culture is not symmetrical and mutual. There is an imbalance of power in this growth and exchange pattern. For example, there has also been an asymmetrical growth in the number of language speakers. Some languages like English and Hindi have seen an increase in the number of users while other native languages lag behind. Fewer English texts need to be translated as more and more people acquire competence in this language. However other languages have adapted to change in technologies and technology in turn has adapted to new languages to increase its reach. Internet content in various languages is increasing and the availability of Google in other languages indicates that not all is lost.

As goods for consumption become available globally and instantly, the movement of ideas on the other hand has been a little slower. Access to foreign goods has not necessarily led to acceptance of the foreign. Sections of societies who were marginalized have moved further towards the margin. It becomes imperative in the changing dynamics of global exchange that all parties be on board. It is here that New Cosmopolitanism provides a way forward and translation as a vehicle of intercultural exchange forms an important component. Barriers exist, as Sheldon Pollock writes, "But this revenant late liberalism reveals, in a more exaggerated form, a struggle at the heart of liberal theory, where a genuine desire for equality as a universal norm is tethered to a tenacious ethnocentric provincialism in matters of cultural judgement and recognition" (Breckenridge: 2002). A cosmopolitan imagination is the need of the hour. For Gerard 
Delanty "the cosmopolitan imagination entails a view of society as an ongoing process of self constitution through the continuous opening up of new perspectives in light of the encounter with the Other" (Delanty: 2009). He further writes, "Translation was once a means to communication and to render another culture intelligible...with the principle that every culture can translate itself and others, cane the possibility of incorporating the perspective of the Other into one's culture" (Delanty: 2009)

Translation of literary texts performs the same fundamental role it did when it first started. One of making familiar an unfamiliar culture as transmitted through the translated texts. Experience of other cultures mediated through the translated texts forms an integral part of cosmopolitan empathy. Beck sees that the metatheory of identity, society and politics as empirically false. He quotes Perlmutter (1969) who sees global cooperation as being more horizontal than vertical. However a cosmopolitan identity does not negate a national identity. What it negates is an identity and responsibility based solely on national boundaries. Beck insists on 'the principle that local, national, ethnic, religious and cosmopolitan cultures and traditions interpenetrate, interconnect and intermingle'. A cosmopolitan world demands not only sympathy for the Other but also an understanding of their views. It desires a plurality of ideas which may not necessarily be harmonious and may call for negotiation between competing world views. But this negotiation must take place in an informed and empathetic atmosphere and not one that is ignorant and bigoted. Translation of texts is thus important for building bridges across the chasm of insularity. Ethnocentrism needs to be transcended. Increasing globalization has also been accompanied by increasing inequalities and increasing parochialism. Nations consume products of modernity without imbibing the fundamental modern value which gives importance to the rights of the individual. Modernising lifestyles have not been accompanied by modern, egalitarian and gender sensitive values. Translation has often been seen primarily as a linguistic and an academic exercise not a political or a social force. In Devy (2003) 
attempts this very exercise. The 'Introduction' to the book talks about the fundamental features of the tribal world view. "They live more by intuition than reason, they consider the space around them more sacred than secular, and their sense of time is personal rather than objective". The translated songs testify to this 'novel' outlook. Negotiation of difference and experience of the Other can be actively fostered by processes of translation. Germany's acceptance of Syrian refugees is an example of this cosmopolitan empathy. It is surely a paradigm shift from the hyper nationalism of the Nazi era.

\section{REFERENCES}

- Appiah,Kwame Anthony. Cosmopolitanism: Ethics In The World Of Strangers. Penguin London, 2006

- Bassnett, Susan and Harish Trivedi. Post-Colonial translation: Theory and Practice. Routledge: New York.1999.

- Beck,Ulrich.Cosmopolitan Vision. Polity Press:Cambridge.2006

- Breckenridge,Carol A. et.al.ed. Cosmopolitanism. Duke University Press.2002

- Cheah,Pheng and Bruce Robbins. Cosmopolitics: Thinking And Feeling Beyond The Nation.University of Minnesota Press: Minnesota,1998..

- Delanty, Gerard. The Cosmopolitan Imagination:The Renewal of Critical Social Theory. Cambridge University Press: Cambridge. 2009

- Devy, G.N. Painted Words: An Anthology of Tribal Literature, Penguin Books India. 2003

- Perlmutter, H. V., The Tortuous Evolution of Multinational Enterprises, in: Columbia Journal of World Business, 1/1969, pp. 9-18.

- $\quad$ http://www.globalization101.org 